revista ANTHROPOLÓGICAS

Ano 23, 30(1): 190-210, 2019

\title{
Gênero, Espaço Social e Identidade: o caso de um povoado em Rewari, no estado de Haryana, India
}

\author{
Subhadra Mitra Channa ${ }^{\mathrm{a}}$
}

O gênero é constituído por um padrão complexo de comportamento e inter-relações sociais, mas tem espaço para manipulação e interpretação individual. Os indivíduos não respondem às situações sociais de maneira uniforme. Por meio de seu próprio gerenciamento do ambiente social existente, cada pessoa pode prevalecer sobre a sociedade para conceder-lhe o 'espaço' que deseja. Esse 'espaço' não precisa levar indivíduos para fora da esfera da interação social. O que tentei mostrar neste artigo é que, dentro de uma cultura, há espaço para os indivíduos exercerem seu individualismo, geralmente de uma maneira que vai contra o padrão normativo e, ainda assim, mantém sua identidade social.

Cultura, Gênero, Espaço social, Interação social, Identidade social.

\section{A constituição do gênero}

Os indivíduos crescem em uma cultura embebidos de noções sobre o que é considerado apropriado como qualidades masculinas ou femininas, o que inclui as disposições da personalidade, características mentais e físicas, a habilidade para performar certas tarefas e uma posição definida na cosmologia. Isso consiste de crenças relacionadas ao poder, pureza, poluição, perigo e a uma superioridade ou inferioridade cosmológica atribuída a cada um dos sexos (Douglas

a Doutora em Antropologia pela Delhi University. Professora da Delhi University. Vicepresidente eleita da International Union of Anthropological and Ethnological Sciences (IUAES). Email: channa.subhadra@gmail.com. 
1970). Esses atributos coletivos informam basicamente as tarefas sociais apropriadas para cada gênero, assim como a divisão do trabalho, esferas e modos de interação, os recursos designados, direitos e deveres, expectativas sociais e uma gama de movimentos físicos e mentais permitidos. Portanto, ligado ao conceito de gênero está o conceito de 'espaço social' - que é físico, mas também um conceito social e psicológico, que delineia a esfera de interação social e as aspirações das pessoas. A noção de gênero é estereotipada, contida e transmitida através de múltiplos canais, tradições orais e escritas, folclore, mitos e moral (Deckard 1979; Quinn 1977; Reiter 1975).

O gênero é constituído por um padrão complexo de comportamento e pelas inter-relações, mas possui alcance para a manipulação e interpretação individual. Os indivíduos não respondem às situações sociais de forma uniforme. Através de seu próprio gerenciamento do ambiente social existente, cada pessoa lida com a sociedade para garantir a ele ou ela o 'espaço' que deseja. Esse 'espaço' não precisa retirar os indivíduos da esfera de interação social. De fato, o que busco demonstrar nesse artigo é que em uma cultura há espaço para os indivíduos exercerem o seu individualismo, muitas vezes de forma contrária ao padrão normativo, e ainda assim manterem sua identidade social. As estratégias para essa manipulação também são culturalmente e socialmente fornecidas em atenção ao que Appell descreveu como 'contra-estrutura':

"É errôneo supor que o conceito de estrutura social não lida com a quebra das leis ou a manipulação das leis. Pois é a estrutura ela mesma que nos provê com os caminhos, técnicas e o conceito mesmo de fazer aquilo que se está ordenado a fazer. Esse domínio pode ser chamado de 'contra-estrutura" (Appell 1988:45).

Os seres humanos, alocados em situações reais, estão equipados com a capacidade para a ação estratégica, inovação e ajuste, o que os permite manipular e fazer escolhas de alternativas mais adequadas aos seus próprios interesses. $\mathrm{O}$ interesse próprio pode ser definido como o posicionamento de si mesmo com mais vantagem em relação 
aos outros, ao mesmo tempo em que simultaneamente satisfaça seus desejos pessoais. Os indivíduos diferem pela sua capacidade para manipulações sociais.

Portanto, apesar da sociedade prover modelos para a construção do gênero, os próprios seres sociais são dinâmicos, e a interação em determinadas situações sociais e instituições é o resultado de coerções e manipulações, de habilidades individuais e da resiliência dos valores e do ethos, os quais recriam e reafirmam, reproduzindo e modificando simultaneamente. Pessoas colocadas em determinados confinamentos do 'espaço social' podem, individualmente ou coletivamente, ousar redefinir e recriar o que é socialmente constituído. Um mecanismo ativo em processo de 'silêncio'. As pessoas talvez ignorem ou desprezem, ou mesmo não falem sobre algo. Em muitos casos esse é um mecanismo cultural para sobrepor aquilo que é contra as normas expressas, mas 'conveniente'. Por exemplo, Paul Hershman, falando sobre a ocorrência do incesto em uma vila Punjabi, escreve: "a atitude geral dos Punjabi é aquela que se as coisas podem ser acobertadas, melhor que sejam esquecidas" (1981:135).

Enquanto discute os mecanismos das regras e sua execução social, Edgerton descreve a morte de uma mulher como punição retributiva por ofensas pré-maritais e extramaritais por parte de seus parentes, dentre os Beduínos de Israel e em muitas partes do mundo árabe. Entretanto, como ele aponta, tal punição retributiva nem sempre é executada se a conduta da mulher é de conhecimento público: "antes que uma morte por honra possa ocorrer, parece, o conhecimento popular deve se tornar um desafio público ou uma queixa” (1985:160). O acontecimento de tal exposição pública depende do apoio do grupo de parentesco da mulher e de sua interpretação da situação, o que depende, em grande medida, de sua posição social. Grupos de parentesco poderosos e solidários podem sempre recorrer ao 'silêncio', a despeito do conhecimento público não dito. Seus dados são apoiados por outros produzidos por etnógrafos como Joseph Ginat e Emmanuel Marx, que trabalharam na mesma região. 
Um dos símbolos chave da cultura Haryana é a honra, ou izzat, que pertence ao coletivo, em primeira instância, à vila, e então à patrilinearidade. Qualquer brecha na honra, deshonra ambas essas coletividades. A honra reside na manutenção da virgindade das meninas, garantindo a endogamia da casta e a honra das mulheres casadas ao observar as regras pertencentes ao incesto e àqueles sustentando o orgulho dos machos da patrilinearidade. Como observado por Chowdhry (1994), é simbolizada pelo purdah observado pela mulher. O dialeto local fala de baat par purdah dalna, o que implica o disfarce e o subsequente silêncio, sugerindo o comportamento de como se nada tivesse acontecido. Portanto, mais relevante que qualquer violação, estas deveriam ser confinadas à patrilinhagem, ou à comunidade da vila. A regra da exogamia na vila foi particularmente útil como o foi a do incesto, fuga e alianças pré-maritais, escondidas quando as meninas em questão se casaram com homens em uma vila distante.

Portanto o conhecimento deve ser convertido em uma expressão vocal para que assuma o status de um ato socialmente reconhecido. A estratégia do silêncio em si mesma faz o ato invisível e socialmente não-existente e sua mais importante dimensão é a conformidade dos atores com o ato. É através do reforço ou efetivação dessa conformação que o poder ou influência dos indivíduos sobre seu ambiente interativo se torna uma consideração importante. A responsabilidade do comportamento é assim enredada numa complexidade de relações e valores, e algumas vezes alguém pode se deparar com casos surpreendentes de indivíduos incomuns que aparentemente estenderam a responsabilização para o seu mais amplo limite e conseguiram se esquivar.

Em outras palavras, "a maneira pela qual o gênero é realizado pode revelar mecanismos através dos quais o poder é exercido e a desigualdade é produzida. Esse exercício do poder, como as etnografias revelam, não é uma hierarquia estabelecida, mas uma luta constante" (West \& Fentersmaker 1995:9). Homens e mulheres, coletivamente e individualmente, lutam na arena do 'espaço social', e mecanismos cul- 
turais como os 'silêncios' e as 'vozes' são as armas dessa luta. Baseada em seu trabalho de campo, Prem Chowdhry escreve:

"As possibilidades dialógicas existentes nas vozes das mulheres rurais em Haryana, no meu ponto de vista, não as mostram como passivas, mas de fato revelam nuanças de uma postura oposta. As mulheres emergem não apenas no reforço das fronteiras da ordem social, mas também as perturbando. A outra voz que emerge é uma voz independente, subversiva da ordem patriarcal em seu contexto específico. Zomba e ridiculariza o controle e a autoridade, e suas várias relações, ao inverter as regras ordinárias do protesto social, não apenas em tempos de festival anual, mas também em outras ocasiões sociais. As mulheres mais velhas talvez usem essa voz como protesto e controle. Elas também podem permitir de bom grado que algumas vozes sejam ouvidas que de outra forma seriam consideradas ameaçadoras" (Chowdhry 1994:18-19).

\section{Relações de gênero em uma vila Khori}

Em meu estudo dos Khori observei como as regras ideais de comportamento são reinterpretadas para acumular comportamentos culturalmente inapropriados. A lógica é que o que não é sabido não existe. Descrevo uma mulher Haryanavi que, na minha opinião, conseguiu criar seu próprio 'espaço social' no qual enfrentou as normas mais evidentes de sua sociedade. Minha impressão dela foi formada pela minha compreensão da cultura dessa região, tanto pelo meu próprio trabalho de campo em uma vila Haryana no distrito de Rewari como através de excelentes contribuições sobre a cultura Haryana, como aquelas de Chowdhry (1994) e Chandoke (1990).

A vila Chameli é uma típica vila multi-casta da Haryana. Os Ahirs são a casta dominante, e têm sido tradicionalmente associados à criação de gado e venda de leite. Como a área é muito árida para uma agricultura em larga escala, tem dependido do gado leiteiro e dos búfalos como forma de subsistência. As outras castas na vila são os Brahmins, os Kumhars, os Chamars, os Bhangis, os Nais, os Dohbis, os Telis, os Jogos e os Bawarias. Os Brahmins são a única casta duas vezes nascida ou alta na vila; o restante são as castas atrasadas $(\mathrm{OBC})$ ou castas pro- 
gramadas (SC). Os Ahirs dominantes, através de uma casta atrasada, são sânscritizados em seu modo de vida. Eles são ritualmente servidos pelos brâmanes, um direito demandado pela virtude da dominância social e econômica.

Por conta de fatores como a introdução da educação formal, proximidade à uma cidade (Rewari) e o recrutamento massivo da população masculina dessa região para o exército - muitas vezes alcançando 50\% em algumas vilas (Chowdhry 1994) - há grande diversidade ocupacional. Há também uma clara separação entre os domínios masculinos e femininos. Na vila, os homens aram os campos e são ativos na política de ambas as vilas e no nível nacional. Os homens de Haryana são fortes e têm fama de serem agressivos. Eles manejam um lathi (um cajado de madeira pesada), que possui diversos simbolismos na cultura local, cuja principal distinção é sua associação com a masculinidade. As mulheres são igualmente fortes e fazem todo o trabalho em casa, como cozinhar, cuidar das crianças e dos animais. Os búfalos precisam de dois banhos por dia, sua comida preparada através do corte de feno e também precisam pastar e ser ordenhados. Apesar de jovens meninos também se ocuparem do pastoreio, o resto do trabalho é feito pelas mulheres. Elas também limpam os viveiros do gado e fazem os bolos de esterco, que são o combustível primário para o cozimento.

Os homens aram os campos e os irrigam, mas as mulheres plantam as sementes e cuidam das mudas. Elas ajudam os homens na colheita, limpeza e armazenamento dos grãos. As mulheres, em geral, cuidam de todos os afazeres domésticos. As mulheres mais jovens fazem a maior parte do trabalho físico, ao passo em que as mais velhas tomam as decisões que envolvem o cuidado de todo o grupo doméstico e as vendas e compras no nível doméstico. Os homens mantém distância da maioria dos afazeres domésticos e, de fato, ficam pouquíssimo tempo dentro da área doméstica. Como Chandoke (1990:223) descreveu claramente, existem três tipos de estruturas residenciais em toda casa Haryanavi - a ghar, gher e baithak. A ghar é ocupada 
por mulheres e crianças, a gher pelo gado e a baithak pelos homens. A ghar Haryanavi ou casa consiste majoritariamente de mulheres e crianças e é o lugar da lareira e dos bens. Na maior parte do tempo os homens ocupam a baithak ou um tipo de sala de encontros onde os homens da vila congregam e se engajam em vários tipos de discussões. Aqui são servidos com chá pelas mulheres e também fumam o hookah. O baithak é onde os hóspedes são entretidos e onde todas as matérias que dizem respeito à vila são discutidas. Os homens também ocupam outros espaços públicos como o chaupal (Chandoke 1977) e o panchayat ghar, o primeiro um tipo de casa comunitária e o último um lugar de encontro para os líderes da vila.

$\mathrm{Na}$ configuração da vila há pouca interação entre marido e esposa, e nenhum dos quartos da casa é designado especificamente para qualquer função, exceto a cozinha. O pátio, que é o centro da casa, está cercado por quartos e é onde as mulheres sentam, fofocam e trabalham. Não é incomum encontrar uma matriarca mais velha sentada numa cama no centro do pátio empunhando um hookah. Apenas as mulheres que alcançaram o status mais alto como chefe feminina de uma casa pode sentar na cama, as outras se sentam no chão ou em bancos e as mais jovens ficam de pé - pelo menos na presença de outras. Durante o dia é difícil encontrar um homem ao redor da casa, exceto pelos muito velhos, que são cuidados pelas mulheres.

A ideologia corrente das pessoas é patriarcal. Os homens afirmam que cabe a eles dominar os negócios da vila, e espacialmente a vila pertence a eles. São eles que ali nasceram, a possuem e ali cresceram. As mulheres são sempre 'de fora'. As meninas solteiras são tratadas como hóspedes temporárias na vila de seus pais e as mulheres casadas ainda são consideradas 'de fora' pois não nasceram na vila de seus maridos. A comunidade, ou biradari, é a associação de machos agnatos. Um grupo mais específico é o dos kunba, literalmente a família (Chandoke 1990:125). As mulheres pertencem à linhagens grupais, as quais são distintas das patrilinhagens exogâmicas que produzem o núcleo da comunidade da vila. Todos os homens da vila, de uma casta 
particular, são irmãos e todas as mulheres que nasceram na vila são irmãs. Os casamentos sempre acontecem fora da vila e fora da gotra. As casadas ou as mulheres maduras são portanto todas 'de fora' dessa biradari masculina que controla os negócios públicos da vila. $\mathrm{O}$ lathi permanece o símbolo da dominação masculina. A humilhação capital a qual uma mulher pode ser submetida é a penetração forçada de sua vagina por um lathi. Tal atrocidade, que é uma forma simbólica de estupro, é uma ofensa séria contra a mulher. Se tal acusação é levantada no panchayat da vila, é convocada uma ação drástica.

$\mathrm{Na}$ medida em que os homens da vila são coletivamente responsáveis pela proteção da honra de suas mulheres, há uma preocupação apenas com o izzat das mulheres dominantes e de castas mais altas. Mulheres de castas mais baixas, que são percebidas como não tendo qualquer honra, foram tradicionalmente sujeitadas ao estupro e humilhação por parte dos homens de castas dominantes, mesmo de sua própria vila. Há uma diferença distintiva na mobilidade física de mulheres de castas altas e baixas: as mulheres de castas altas se sentem seguras para ir a qualquer lugar na vila e são vistas ativamente pastoreando o gado, abastecendo a água, buscando lenha e forragem. Mulheres de castas baixas são mais cautelosas, elas não permitem que suas mais jovens, especialmente as solteiras, saiam para muito longe da casa. "Os homens Ahir protegem a honra de suas próprias mulheres, mas humilham nossas mulheres. Ninguém protegerá uma Chamar ou uma mulher de casta baixa", disse-me uma mulher Chamar.

Apesar da dominância da ideologia patriarcal, as mulheres comumente se organizam contra os homens. Nesse contexto foi interessante observar os comportamentos eleitorais das mulheres. Contrariamente à crença difundida de que as mulheres votam de acordo com a patrilinhagem de seus maridos, me informaram que uma mulher pode deliberadamente votar contra a preferência de sua linhagem afim; ao fazer isso ela poderia ganrah imensa satisfação psicológica. Como todos os atos, sua transgressão permaneceu encoberta e não dita, compartilhada apenas com as mulheres de sua sororidade secreta contra os ho- 
mens. Eles podem suspeitar de tal transgressão mas nada podem fazer. As mulheres se sororizam e satisfazem suas próprias sessões de fofoca. Apesar do sexo entre um homem e uma mulher ser uma atividade escondida, e o romance não ser aceito como parte mesmo das fofocas, as mulheres zombam e brincam bastante sobre sexo quando estão juntas. Quando estão com os homens, elas permanecem distantes.

As mulheres podem ser categorizadas como as meninas solteiras da vila, noras ou jovens mulheres casadas, e a sogra e chefe da casa. Meninas observam no purdah, vagam livremente pela vila, e como em muitos lugares de Haryana, frequentam a escola. Em 1992, o envolvimento de crianças do sexo feminino nas escolas era de 100\%. Mães e avós agradam o menino, apesar dos avôs usualmente mimarem as netas. As mães dão aos meninos petiscos deliciosos, enquanto as meninas comem vegetais crus como rabanetes, cenouras, ervilhas e grão de bico enquanto trabalham nos campos, adequadamente bem nutridas.

A nova nora tem o mais baixo status na casa. A despeito da ideologia corrente, há pouca dominação direta das mulheres pelos homens uma vez que seus domínios permanecem separados. Mulheres jovens trabalham diretamente sob a supervisão das mulheres mais velhas nas casas. Observei que enquanto há pouca interação com a esposa, o marido geralmente demonstra cuidado, mas há pouco que ele possa fazer para ajudar sua esposa. É a mulher mais velha da casa que mantém as chaves da dispensa e é ela que distribui a comida e outros itens para os demais membros da casa. Se um jovem marido sente que sua mãe não está dando comida em quantidade adequada a sua esposa, ele pode protestar verbalmente, mas ele não tem controle sobre as ações das mulheres sênior.

Caso uma sogra morra ou um casal construa uma unidade nuclear, a esposa assume o papel de tomar as decisões no seio da casa. As noras das vilas observam o purdah de todos os homens afins que são mais velhos que seus maridos. Seja na visão dos outros, as jovens mulheres mantém suas faces cobertas todo o tempo. As mulheres mais velhas abandonam o véu, exceto quando na presença de um homem 
afim mais velho. A autoridade vem com a idade. É a mulher mais velha que manda na esfera doméstica e indiretamente, através de seus filhos, também influencia no domínio público. Na cultura Haryanavi, a mais importante relação homem-mulher, e na qual a mulher é totalmente dominante, é aquela entre uma mãe e seu filho. A manifestação mais explícita desse laço é a amamentação simbólica pública de um noivo pela sua mãe logo antes da cerimônia do casamento. Portanto, mesmo quando um homem está prestes a se casar e formar um laço com outra mulher, sua relação com a mãe é destacada.

Os casamentos são estritamente arranjados pelos mais velhos e usualmente pelas mulheres da casa. Eles tomam lugar idealmente através da exogamia estrita gotra e pela endogamia de casta ou sub-casta. Há uma limitação para um novo casamento tanto para a viúva como para o viúvo, de acordo com as leis do levirato e sororato , a morte da pessoa sendo substituída por um irmão ou irmã real ou classificatório. Tradicionalmente a viúva foi herdada pelo irmão mais novo de seu marido. Uma falta crônica de mulheres levou à prática da poliandria fraternal e do casamento inter-casta. Como Chowdhry (1994) aponta, o recasamento das mulheres como também a lassidão sexual tem sido uma característica inerente da vida social nessa região. Como ela escreve:

“A aceitação de um 'clima social liberal' tem como base a importância das mulheres para a economia agrária, tanto no seus aspectos produtivos como reprodutivos... Três fatores alinhados determinam sua natureza e a extensão para a qual o patriarcado rural é acomodado. Esses incluem: (a) a emigração dos homens, (b) o recrutamento em alta escala para o Exército Indiano-Britânico e (c) a baixa taxa de crescimento populacional nessa região" (Chowdhry 1994:20).

A relação do marido e da mulher permanece enigmática. Nos primeiros anos do casamento há pouca interação entre os dois exceto o ato sexual encoberto para gerar crianças. As esferas de atividade dos homens e mulheres adultos são claramente separadas. Os meninos formam sua única relação próxima com uma mulher ou mulheres 
enquanto são parte da esfera doméstica, quer dizer, com suas mães e avós, tias e irmãs.

O laço entre irmão e irmã é de proximidade, e os homens tem uma grande responsabilidade na proteção das suas irmãs e de todas as suas irmãs classificatórias. A maior parte da violência e das contendas na região se origina daquilo que chamam de 'proteção' da honra das irmãs. Os rapazes universitários possuem um laço de honra na proteção das moças universitárias de suas vilas. Apesar de altercações poderem ocorrer entre grupos de rapazes de vilas diferentes sobre a provocação de garotas. Uma irmã é também uma pessoa de confiança para um homem, uma vez que ela é da mesma biradari que ele. As afins são 'de fora'. No momento do parto da criança de uma mulher, a irmã do marido é chamada para cuidá-la. Ela é vista como a pessoa de maior confiança para cuidar da criança que pertence à linhagem de seu (próprio) irmão, ao invés de mulheres que são afins.

Ligações pós-matrimônio não eram desconhecidas; ao invés disso eram até frequentes como mostram meus dados e aqueles de Chowdhry. Uma vez que o a noção feminina de pessoa é primariamente derivada do papel da mãe ao invés da esposa ou parceira sexual, os ideais de feminilidade concentram mais do maternal do que das expectativas do papel sexual. As mulheres podem se safar por serem esposas infiéis, mas nunca por serem mães desleixadas. $\mathrm{O}$ aspecto mais importante do casamento, como demonstrado por antropólogos, para as sociedades baseadas nos agrupamentos por parentesco como a linhagem, é o reabastecimento de crianças do sexo correto (Leach 1995). Nesse caso, é a criança do sexo masculino. O conceito de paternidade é primariamente social; a paternidade genética é pouco reconhecida ou de pouca importância. Uma mulher joga o papel mais importante na sociedade ao reproduzir a linhagem masculina, ao parir e criar crianças saudáveis. O levirato é comum nessa região e também o foi uma forma de poliandria leviral, na qual a mulher pertence mais à patrilinhagem do que a um marido exclusivo. Entretanto, normas relacionadas a isso estão em plena transformação no presente. A separação dos 
domínios masculino e feminino também leva à construções de gênero que excluem os maridos mas incluem os filhos. Similarmente para os homens, sua masculinidade é derivada não de sua sexualidade vis-a-vis de suas esposas, mas do leite de suas mães. Um homem é um homem por conta de seu ma ka dudh (leite materno) e ele é comprometido na defesa da honra de sua irmã, que é filha de sua mãe e nutrida com o mesmo leite. Há pouca ênfase prática ou cultural na defesa da honra de sua esposa, com quem só se mantém uma relação periférica.

\section{História de Chameli}

Dentro do quadro das instituições sociais e cultura dessa região, Chameli foi uma voz que desafiou a ordem social, não por simplesmente ter tomado a decisão de retirar o véu, mas também por suas ações. É esse desvelamento que posicionou Chameli à parte e que colocou um desafio às normas sociais existentes. Chameli era uma mulher Brahmin de meia idade casada com um homem aposentado do exército. Ela tinha vários filhos já adultos. Lembro de meu primeiro encontro com Chameli . No meu primeiro dia na vila eu estava sentada no lado de fora de uma casa reconhecendo o campo quando uma mulher cruzou o meu caminho. Ela era forte, de meia idade, vestida como uma mulher da vila e carregava um pote de água no quadril. Ela caminhava do poço em direção à sua casa. Ela me olhou, parou e perguntou quem eu era. Ao escutar que eu vinha de Delhi para estudar a vila, ela se sentou ao meu lado e colocou o pote no chão.

"Sou Chameli", ela disse como forma de introdução. "Sou a chefa da mahila mandali daqui. Vou ajudá-la em tudo o que precisar". Fiquei impressionada com sua atitude e determinação, apesar de sua pele ser esburacada de cicatrizes de varíola. Ela falou de forma assertiva e confiante. Uma das mulheres que estava sentada nas proximidades ressaltou, "Chameli, com certeza você poderá ajudá-la pois você é a única que consegue fazer as coisas do seu jeito". No final de nossa longa conversa, Chameli me convidou para ir a sua casa. Durante a minha estadia de seis semanas na vila interagi com ela quase todos os dias. 
Chameli é a filha mais velha de um rico Brahmin lambardar (proprietário de terras), agora morto, que foi o sarpanch (líder) de sua vila e proprietário de aproximadamente 300-400 bighas (aproximadamente 1000 jardas quadradas) de terra. Chameli tem uma irmã mais nova e quatro irmãos. Sua irmã tem dois títulos, um bacharelado e uma licenciatura, e é solteira. Ela usa roupas masculinas, vive na casa do pai, monta um cavalo e é totalmente independente. Ela até ingressou na polícia de Haryana por algum tempo. Chameli, por outro lado, não frequentou a escola, se casou quando tinha 10 anos e sua gauna aconteceu quando tinha 14 anos.

Desde quando era muito nova, Chameli diz que já não se sentia satisfeita com a domesticidade e que desejava um papel público. Enquanto seus sogros ainda eram vivos ela começou a se interessar pelos assuntos da vila. Ela participava, como disse, sempre que ela achava que uma injustiça estava sendo cometida. Seu marido era do exército e ficava a maior parte do tempo longe de casa. Claramente, seus sogros mais velhos não podiam lidar com o temperamento explosivo de sua jovem nora. Em pouco tempo Chameli se tornou uma figura chave na vila; as pessoas a escutavam.

Perguntei-lhe se seus sogros interferiram em suas atividades públicas. "Ninguém pode me parar quando acho que estou fazendo a coisa certa", foi a sua resposta firme. As áreas que mais mobilizavam Chameli eram aquelas envolvidas com o assédio físico e mental contra as mulheres. O envolvimento ativo de Chameli na vida pública da vila co-existia com sua vida doméstica. Seu primeiro filho nasceu quando ela tinha 15 ou 16 anos. Depois disso ela teve seis filhos, com um intervalo de dois ou três anos entre cada. As duas filhas mais velhas se casaram ao mesmo tempo; ambas se formaram e são hoje professoras primárias. A terceira filha também se casou. No momento do meu trabalho de campo, dois filhos e uma filha, com idades de 22, 18 e 16 anos, respectivamente, ainda viviam com ela; todos solteiros. $\mathrm{O}$ filho mais velho trabalhava em uma cidade próxima de Rewari, ao passo em que os dois mais novos estavam estudando. 
Pelas costas as pessoas da vila falavam mal de Chameli. Entretanto, eles aceitavam sua autoridade quando ela os confrontava. Uma das principais razões das críticas era sua ligação com o diretor da escola da vila, da casta Bawaria. Os Bawarias são um dos grupos de casta mais baixos na vila, e são membros das Castas Programadas. O diretor era um viúvo quando ele e Chameli se juntaram. Ele agora tem uma jovem esposa e filhos pequenos, mas Chameli é a chefe socialmente reconhecida de sua casa. Um dia perguntei a alguns meninos onde poderia encontrar Chameli. Eles disseram que ela estava "na casa dela" e, para a minha surpresa, me levaram à casa do diretor. Chameli estava em uma cama no pátio, como faria uma chefe de casa. A esposa mais jovem do diretor estava correndo de lá para cá, levando recados, com sua face completamente velada. Chameli estava lhe dando ordens. Na minha chegada, ela ordenou que a esposa do diretor me servisse um chá. Quando o diretor chegou, ele sentou ao lado de Chameli, na cama. Nessa cultura um homem raramente se senta ao lado de sua esposa em público. Se um marido chega e senta, a esposa ou se levanta ou senta no chão. Mas Chameli continuou sentada ao lado do diretor enquanto conversava. Tudo isso aconteceu às vistas de outros vilageanos, que estavam aglomerados ao redor do pátio.

Significantemente o diretor me cedeu elonquentes argumentos sobre amor e casamento. De acordo com ele, o casamento significa o enlaçamento de corações, não uma cerimônia ritual ou social formal. Chameli o apoiou integralmente, balançando a cabeça em sinal de aprovação. Seus gestos e o seu comportamento em geral deixou evidente que sua relação tinha um forte componente sexual. Enquanto muitos vilageanos apresentavam uma narrativa desaprovadora desse laço, concederam-lhes reconhecimento social à relação ao admitirem Chameli como a chefe da casa do diretor. Naquilo que interessava os vilageanos, a casa era tanto de Chameli como o era de seu marido. Apesar de Chameli ter acesso às duas casas, o diretor nunca visitou a casa do esposo de Chameli ou vice versa. Entretanto os filhos, tanto 
de Chameli como do diretor, tinham acesso à ambas as casas e tratavam ambas como se fossem suas próprias. Os dois atores invisíveis nesse drama eram a esposa do diretor e o marido de Chameli. A primeira, uma jovem mulher em seus vinte e poucos anos, levava suas tarefas diárias cuidando do purdah e nunca falou uma só palavra, exceto com as crianças. $\mathrm{O}$ marido de Chameli ficava a maior parte do tempo fora da vila. Mas quando estava presente mantinha o silêncio, nunca falando com visitantes, e confinando a si mesmo dentro de sua casa.

\section{Espaço como reflexão da organização social}

A organização social de uma vila Haryanavi dá importância primária à duas normas sociais - o confinamento das mulheres à casas afins e a segregação estrita, ambas sociais e físicas, dos domínios masculino e feminino. As regras do casamento reforçam uma transferência completa da mulher para a patrilinhagem do marido, que é reforçada pelos costumes do levirato e do sororato. Apesar de raramente os casamentos serem estritamente monogâmicos, as ligações extra-maritais são comumente confinadas aos homens da patrilinhagem dos maridos. As ligações sexuais fora da patrilinhagem também se formaram, mas geralmente por viúvas. Para uma mulher casada transgredir a fronteira de sua casa afim, como Chameli fez, era uma violação das normas. Entretanto, na ausência do puritanismo como valor, não era uma violação séria - a despeito de sua ligação, a estrutura das relações sociais não foram afetadas uma vez que seus filhos eram reconhecidos como sendo de seu marido. Por outro lado, as relações básicas de gênero na vila reproduziam a si mesmas através da separação dos domínios masculino e feminino. A transgressão de Chameli na vida pública ameaçava a base fundamental desses domínios, criando uma sobreposição do espaço social o qual estavam ambos confusos e indesejáveis do ponto de vista da comunidade da vila.

Sentada no seu pátio um dia, escutei alguns homens gritando "Ho Chameli" lá de fora. Ela se levantou imediatamente para ver, sem cobrir a sua face e voltou após 20 minutos. Uma vez que a chamaram 
em um tom tão familiar e como ela não observou o purdah, perguntei se eles eram homens de sua vila natal (que seriam seus irmãos classificatórios). "Oh, não", ela respondeu. "Esses são homens de uma vila vizinha que vieram comprar um búfalo. Ajudei-os a chegar a um acordo". Essa era uma tarefa usualmente feita por homens. Ademais, a forma das pessoas da vila tratarem Chameli era como se fossem tratar um homem. Ao questioná-la sobre a não observância do purdah, Chameli me disse que não acreditava nele. "Acredito que a honra existe nos seus pensamentos, sentimentos e não na cobertura de sua face”, respondeu-me.

Como chefe da mahila mandali, e membro da gram panchayat (conselho da vila), Chameli também viajava para fora da vila na companhia de homens que não eram seus parentes. Essas violações grosseiras das regras de governo do espaço social eram comumente mencionadas pelos vilageanos como exemplo de sua "falta de modéstia". Entretanto, a despeito de todo o criticismo encoberto, nenhum vilagiano a excluía. Ela tinha acesso a todas as casas, e muitas vezes as mulheres se referiam às suas maneiras autoritárias. "Quem pode te impedir de fazer o que gosta, Chameli?", uma mulher brincou com ela ao cruzar o seu caminho. A mahila mandali (que recebe um orçamento anual de Rs. 8.00010.000 do governo) não é popular no corpo social da vila.

A esposa do irmão mais velho do marido de Chameli é a tesoureira e a esposa do diretor é a secretária. Existem oito membros no núcleo desse grupo, todas mulheres de meia-idade ou mais velhas da vila. Nenhuma jovem mulher é autorizada por seus parentes a participar da mandali, cuja tarefa principal é um tanto inócua de organizar os kirtans (reuniões religiosas com música) semanais. A maior parte das pessoas pensavam que a mahila mandali não é nada além de um veículo usado por Chameli para chegar aos seus próprios objetivos. As mulheres Chamar diziam que Chameli defende as castas como todas as outras mulheres de castas altas na vila e que ela fazia as mulheres intocáveis da vila se sentarem separadamente enquanto as mulheres de castas altas enchiam seus potes. 
Mulheres mais velhas, que alcançaram a medida de sua independência na hierarquia doméstica, tinham a opção de ampliar seu espaço social através da mahila mandali. Elas cobravam semanalmente 02 Rs. dos membros com os quais coordenam dois centros de educação infantil. Os kirtan mandalis são usados por organizações voluntárias para transmitir mensagens sobre planejamento familiar, preservação ambiental e harmonia comunitária. Usando a mídia tradicional das músicas religiosas e pequenas encenações, essas mensagens são transmitidas em uma linguagem que os vilageanos podem entender. Existem mandalis (associações) em muitas áreas de Haryana e Rajasthan, que servem ao propósito de promover a reunião dos vilagianos, especialmente das mulheres, para receber essas mensagens sociais. É por isso que Chameli é apoiada tanto pelas agências voluntárias como governamentais. Ela, ocupou não apenas o espaço dos não-homens, localizado entre aqueles ocupados pelos homens e mulheres da vila, mas também sobrepôs o espaço da vila e do mundo de fora. Uma razão pela qual ela pode manter esse espaço social não-normativo na vila é parcialmente por conta do apoio que ela tem de agências e indivíduos de fora da vila.

Em sua ligação com o diretor da escola, Chameli transgrediu as normas das esposas e da endogamia de casta. Entretanto, como já discutido, a ausência de uma base bramânica significa que as normas relacionadas à ambas as instituições são frouxas na cultura Haryanavi. A lassidão sexual, especialmente de uma mulher casada, foi aceita mas dentro de limites de tolerância estabelecidos por barreiras normativas. As razões para isso se assentam em um laço um tanto fraco entre o marido e a mulher e na ausência da valia marital da santidade da cama do casal. O marido de Chameli se encaixava na fenda do marido migrante, e como muitos outros similarmente localizados, aceitava essa posição com tranquilidade. Tendo transgredido as normas de pureza sexual para uma mulher brâmane ao manter um relacionamento com um homem de uma casta mais baixa, Chameli foi, entretanto, cuidadosa na preservação dessas normas nas suas próprias interações do dia-a-dia 
ao manter a distância regulatória pureza-perigo dos membros de castas baixas. Sua ligação com o diretor não teria levantado tantas sobrancelhas e conclamado tanto criticismo como aconteceu se caso ela não tivesse transgredido a lei do silêncio: não era tanto o ato em si mesmo mas sua pouca inibição e recusa de fingir o envolvimento que trouxe o criticismo. Além disso, ela era culpada por violações muito mais sérias de normas, como ter cruzado do domínio doméstico ao público.

O espaço doméstico e público é uma oposição fundamental no mapeamento do espaço social na sociedade Haryanavi (veja também Ardener 1981); é a metáfora raiz informando a construção dos papéis de gênero. Na medida em que o espaço social, as normas e os papéis são claramente definidos na teoria, na prática há uma luta constante por controle e liberdade de escolha. Não obstante, práticas encobertas formam uma subcorrente em relação às práticas abertas, nas quais os atores jogam seus jogos à sua própria satisfação psicológica e emocional. Por exemplo, a esposa ideal é aquela que funde a si mesma com a patrilinhagem de seu marido. $\mathrm{Na}$ realidade, o laço emocional e sentimental com sua casa natal nunca é quebrado e continua através de fortes laços que uma mulher mantém por toda a vida com seu irmão. De fato, como um dizer das pessoas de Haryanavi proclama, se tiver de escolher entre um filho, marido ou irmão, uma mulher escolheria seu irmão em detrimento do marido/filho, pois se o marido vai embora ou morre, um segundo casamento é possível, e similarmente um novo filho pode sempre ser concebido, mas um irmão é insubstituível. Isso indica o valor do lugar da mulher nas suas relações na casa natal em detrimento de suas relações afins.

Dois aspectos cruciais das relações de um indivíduo com o ambiente social são a manipulação e o poder; esses são intrinsecamente ligados ao conceito de responsabilização, como discutido anteriormente nesse artigo. Chameli, em sua manipulação das relações sociais, atingiu um equilíbrio correto, ela gerenciou a responsabilização ao aderir às normas de mais importante status para as mulheres em sua sociedade, nomeadamente a maternidade. Ela criou 
as crianças para a linhagem de seu marido e os nutriu de forma impecável (não há questionamento da paternidade genética aqui). Dessa forma ela cumpriu com a principal expectativa relacionada a ela como esposa. Como corroborado por outros autores (Chowdhry 1994), maridos ausentes, por exemplo, aqueles que estavam no exército, não ficavam injustamente preocupados com a castidade de suas esposas, de fato, a separação completa do espaço físico para os homens e mulheres, inibia uma ligação íntima e emocional entre ambos. A poliandria fraternal implícita também leva a uma ausência de possessividade sexual.

A mais importante das tarefas de uma esposa, tanto doméstica como reprodutiva, foi cumprida por Chameli, dando pouca margem ao seu marido e sua família para descontentamento. Sua relação extra -marital era vista com desaprovação, não porque era extra-marital, mas porque envolvia a transgressão da regra da casta de hipergamia, onde uma mulher de casta alta não deve manter um laço com um homem de casta baixa (o oposto sendo permitido e mesmo frequente). Ademais, seu comportamento e falas eram contra as normas do silêncio, uma arma comumente usada pelas mulheres em sua guerra subversiva contra a dominação patriarcal. Onde Chameli se diferenciava de outras era na sua franqueza na demanda de seus direitos como indivíduo e na demanda de um espaço social o qual não era seu pela convenção social. As mulheres em uma sociedade patriarcal são conhecidas por exercerem grande influência pública através de sua manipulação e controle dos homens. Chameli era diferente pois transformava essa influência invisível em visível ao ocupar papéis masculinos.

\section{Nota do Editor:}

Título em inglês "Gender and Social Space in a Haryana Village. Nova Delhi". Publicado originalmente em Indian Journal of Gender Studies, vol.4, no. 1, páginas 21-34, 1988. 


\section{Referências:}

APELL,G.N.1988. "Emergent Structuralism: The Designofan Inquiry System to Delineate the Production and Reduction of Social Forms". In APPELL, G. \& MADAN, T. (eds.): Choice and Morality in Anthropological Perspective, pp. 44-60. New York: State University of New York Press.

ARDENER, Shirley. 1981. "Ground Rules and Social Maps for Women: An Introduction”. In ARDENER, S. (ed.): Women and Social Space: Ground Rules and Social Maps, pp. 11-32. London: Oxford University Women's Studies Committee.

CHANDOKE, S.K. 1977. “Chaupal \& Mdash: The Man’s Community Place in a Jat Village of Haryana India”. Urban and Rural Planning Thought, 20(1):2431.

. 1990. Nature and Structure of Rural Habitations. New Delhi: Concept Publications.

CHOWDHRY, Prem. 1994. The Veiled Women: Shifting Gender Equations in Rural Haryana, 1980-1990. Delhi: Oxford University Press.

DECKARD, B.S. 1979. The Women's Movement. London: Harper and Row.

DOUGLAS, Mary. 1970. Natural Symbols: Explorations in Cosmology. London: Barrie and Jenkins.

EDGERTON, Robert B. 1985. Rules, Exceptions and the Social Order. Berkeley: University of California Press.

GINAT, Joseph. 1979. "Illicit Sexual Relationships and Family Honour in Arab Society”. Israel Studies in Criminology, 10:179-202.

HERSHMAN, Paul. 1981. Punjabi Kinship and Marriage. Delhi: Hindustan Publishing Company.

LEACH, A. R. 1955. "Polyandry, Inheritance and the Determination of Marriage". Man, 55:182-86.

MADAN, T.N. 1988. "The Sonas Saviour: A Hindu View of Choice and Morality”. In APPELL, G. \& MADAN, T. (eds.): Choice and Morality in Anthropological Perspective, pp. 137-56. New York: State University of New York Press.

MARX, Emanuel. 1976. The Social Context of Violent Behaviour: A Social Anthropological Study inan Israeli Immigrant Town. London: Routledge and Kegan Paul.

QUINN, Naomi. 1977. “Anthropological Studies on Women's Status”. Annual Review of Anthropology, 6: 181-225.

REITER Raina. 1975. Towards an Anthropology of Women. New York: Monthly Review Press.

ROSALDO, Michelle \& LAMPHERE, Louise. 1974. Woman, Culture and Society. Stanford: Stanford University Press. 
Sapir, E. 1916. "Terms of Relationship and the Levirate". American Anthropologist, $18: 327-337$.

WEST, Condance \& FENSTERMAKER, Sarah. 1995. "Doing Difference". Gender and Society, 8(1):9-30.

\begin{abstract}
Gender is constituted by a complex pattern of behaviour and social inter-relationships but has scope for individual manipulation and interpretation. Individuals do not respond to social situations uniformly. Through his or her own management of the existing social environment, each person can prevail upon society to grant him/her the 'space' they want. This 'space' need not take individuals outside the sphere of social interaction. What I have tried to show in this paper is that within a culture, there is space for individuals to exert their individualism, often in a manner which goes against the normative pattern, and yet retain their social identity.
\end{abstract}

Keywords: Culture, Gender, Social space, Social interaction, Social identity.

Tradução e Revisão Técnica: Felipe Bruno Martins Fernandes (UFBA)

Recebido em Junho de 2019.

Aprovado em Julho 2019. 